\title{
ECODESIGN DE SUPERFÍCIE: UM ESTUDO DE CASO
}

\author{
Adriana Gralow \\ UNOESC \\ adriana.gralow@gmail.com \\ Luiz Vidal Gomes \\ PPDESDI-UERJ \\ luizvidalgomes@gmail.com
}

Resumo: O presente artigo apresenta estudo sobre projeto de interiores com base em raciocínio de sistemas ecológicos (ecodesign), a partir da reutilização da madeira proveniente do descarte em indústrias moveleiras e de esquadrias, a fim de criar superfícies passíveis de aplicação no espaço interno da biblioteca pública de Guaraciaba, SC. O objetivo é valorizar e promover o ambiente ecologicamente correto destinado à cultura e à educação criativa e projetual. Este estudo tem como base a pesquisa bibliográfica e aplicação de principais teorias no estudo de caso, com o intuito de definir, conceituar ecodesign e seu papel no projeto de produto para superfície de ambientes públicos. O estudo apresenta diferentes propostas de aplicação de madeira certificada em superfícies no ambiente, evidenciando os benefícios que esse material pode proporcionar a ambientes públicos, sem desmerecer o meio ambiente, projetando com base em reutilização de resíduos materiais.

Palavras-chave: ecodesign, design de superfície, biblioteca pública.

\begin{abstract}
This article presents study on interior design based on reasoning of ecological systems (ecodesign), from the reuse of wood from disposal in furniture industries and frames in order to create surfaces capable of application in the internal space of the public library of Guaraciaba, SC. The goal is to enhance and promote the environment-friendly for the culture and creative architectural design and education. This study is based on the literature and application of major theories in the case study in order to define, conceptualize ecodesign and its role in product design for surface public environments. The study presents different wood certified application proposals on surfaces in the environment, highlighting the benefits that this material can provide public environments, without disregarding the environment, designing based on reuse of waste materials.
\end{abstract}

Keywords: ecodesign, surface design, public library. 


\section{INTRODUÇÃO}

A reutilização de materiais é um tema bastante relevante quando falamos em sustentabilidade ambiental. Dar vida a um material que já é considerado lixo nem sempre é tarefa fácil, visto que é necessário estudar uma nova forma, um novo conceito e uma nova função para, então, transformá-lo em um produto de alta qualidade.

Segundo Straliotto (2008), a reutilização de determinados produtos e/ou materiais contribui significativamente para a diminuição do impacto ambiental gerado pelos mesmos no seu descarte, sendo esta, uma das principais funções do ecodesign. Assim, a criação de padrões gráficos para diferentes superfícies e a utilização de materiais alternativos torna-se importante recurso de valorização do ambiente.

O principal objetivo deste estudo é criar superfícies a partir da reutilização da madeira oriunda do descarte em indústrias moveleiras e de esquadrias, localizadas no extremo oeste do estado de Santa Catarina, a fim de aplicá-las na biblioteca pública do município de Guaraciaba. Os objetivos específicos incluem a investigação do ambiente com base em observações diretas e a aplicação do ecodesign na criação de superfícies como forma de valorizar o espaço da biblioteca, favorecendo a visitação de um maior número de leitores.

O interesse por esta pesquisa surgiu a partir da intenção dos autores em promover a biblioteca pública de Guaraciaba que, assim como inúmeras outras bibliotecas, não possui elementos capazes de incentivar e fortalecer o hábito da leitura. Muitas vezes, o descaso para com a biblioteca é consequência da estrutura precária e, por outras vezes, devido, justamente, à ausência de elementos convidativos. Estes elementos, quando aplicados de maneira coerente, vêm ao encontro do público, de modo a propiciar a visitação e a apreciação do espaço.

Esta pesquisa baseia-se na investigação e construção de conhecimentos teóricos sobre ecodesign e design de superfície buscando aspectos relevantes no que diz respeito ao uso de padronagens como elemento de valorização da biblioteca pública de Guaraciaba. A fundamentação teórica seguiu a abordagem dos autores Cândido, Straliotto, Costa e outros, que contribuíram expressivamente na elaboração conceitual sobre o ecodesign. A construção do conteúdo sobre design de superfície é apresentada por Rubim e Freitas. Quanto à estruturação de conceitos e funções da biblioteca pública, considerou-se a Fundação Biblioteca Nacional (FBN).

\section{FUNDAMENTAÇÃO TEÓRICA}

\subsection{Projetos para ambientes ecologicamente corretos (ecodesign)}

Apenas para iniciar, retomamos a algo perfeitamente sabido: é a partir da industrialização (Séc. XVIII e Séc. XIX) que irreversíveis mudanças ocorreram na sociedade, sendo a principal delas o aumento do consumo de produtos, e, como consequência direta, o aumento de burguesia, possuidora de grande poder aquisitivo e, vaidosamente, preocupada aparência fosse no vestir, no comer e no morar. Este acentuado aumento de produtos de consumo nos países industrializados, culminou no rápido esgotamento das matérias-primas, apesar do crescimento contínuo da taxa populacional. A interseção desses dois fenômenos (um antropológico e outro tecnológico), também resultou em degradação do meio ambiente, contribuindo assim para a desestabilização e a quebra da sociedade industrial. (Cf. BÜRDEK, 2006). 
A modernidade com suas novas tendências de consumo desenfreado ocasionado pelo capitalismo desenfreado são os principais responsáveis pelo desequilíbrio ambiental. Desde meados do Século $X X$, a necessidade de se pensar alternativas que desencadeiem ações reversas, isto é, ações em direção ao equilíbrio dos sistemas ecológicos. Essa relação de equilíbrio entre o mundo dos produtos industriais e a poluição ambiental começa, então, a ser pesquisada e estudada através de projetos ecologicamente corretos, ou seja, pelo ecodesign. (MESACASA; CORONA; MELLO, 2010).

Poder-se-ia definir ecodesign como "uma atividade de projeto voltada para o desenvolvimento sustentável de produtos, através de princípios como a diminuição de volume material, de resíduos e de custo ambiental dos produtos". (STRALIOTTO; GONÇALVES, 2008, p.3). É preciso planejar um produto desde a primeira etapa de desenvolvimento, pois, qualquer ação precoce coloca em risco o resultado final do projeto. Ecodesign, destarte, ...

"[...] diz respeito ao ato de projetar produtos, com a preocupação focada no ambiente e em todo seu ciclo de vida, evitando ou diminuindo agressões ao ecossistema, buscando, mediante a correta utilização e Seleção dos Materiais ou processos de fabricação, facilitar, de alguma maneira, o reuso, a desmontagem e a reciclagem dos materiais e produtos." (CÂNDIDO, 2008, p. 18).

O uso de métodos de projetação valendo-se de procedimentos \& técnicas do ecodesign enfatiza a diminuição do desperdício e da poluição ambiental, promovendo uma relação harmônica entre o desenvolvimento econômico e a preservação ambiental. Costa e seus colegas salientam que o "Ecodesign é uma concepção ou abordagem da área de design, que associa o que é tecnicamente possível no campo das tecnologias limpas, com aquilo que é culturalmente desejado no campo da consciência ambiental". (COSTA et al., 2010, p.14). Em outras palavras, o ecodesign prioriza as condições naturais, reconsiderando as relações entre homem e natureza.

Para Cândido (2008, p. 18), “O Ecodesign, na atividade de desenvolvimento de produtos, procura incorporar a variável ambiental, considerando o meio ambiente com mesmo grau de importância, como a eficiência, estética, custo, ergonomia e funcionalidade". Neste contexto, cabe salientar que o ecodesign deve ser integrado na fase de concepção, considerando todo o ciclo de vida do produto, desde a extração de matérias-primas até o descarte.

Cândido (2008) ainda descreve que, em relação ao ciclo de vida, o ecodesign abrange cinco etapas fundamentais, sendo elas: seleção de materiais, otimização da produção, sistema eficiente de transporte, redução do impacto na fase de uso e fim da vida útil. Essas estratégias visam a aplicação de materiais que gerem baixo impacto ambiental, utilização de processos de produção mais limpos e redução do consumo de energia na indústria, além da reutilização, redução e reciclagem do produto.

\subsection{Design de superfície}

O projeto para o desenho de composição ou escolha de materiais para serem aplicados em superfícies e acabamentos, Design de Superfície (DS), é uma das atividades projetuais e criativas do Design. Assim como as outras especialidades, (design de produto, design de moda, design gráfico, web design, design de interiores), 
DS depende da interdisciplinaridade com diferentes campos fabris para alcançar o seu propósito.

Camila Jafelice, designer brasileira, comunica que há poucos lugares onde se possa encontrar definições acadêmicas sobre "Design de Superfície". Há muita informação, mas pouca conexão entre o que é projeto e o que é desenho de padrões usados nos acabamentos de superfícies, sejam eles para uso em objetos de arte, seja para aplicação em produtos industriais. Como no projeto de superfícies para acabamentos e nos desenhos formadores de padrões se requer exploração de processos comuns às indústrias, compreenderemos, neste artigo, "Design de Superfície pode ser representado pelas mais diversas formas, desde que aceitemos que qualquer superfície pode receber um projeto". (RUBIM, 2010, p. 35). A partir deste trecho, é notória a importância do Design de Superfície, principalmente no que diz respeito às inúmeras possibilidades projetuais que estão ao nosso dispor, presentes em nosso diaa-dia.

"O design de superfície visa a trabalhar a superfície, fazendo desta não apenas um suporte material de proteção e acabamento, mas conferindo à superfície uma carga comunicativa com o exterior do objeto e também com o interior, capaz de transmitir informações sígnicas que podem ser percebidas por meio dos sentidos, tais como cores, texturas e grafismos." (FREITAS, 2011, p. 17).

Rubim (2010) salienta que as aplicações do design de superfície são inúmeras, sendo as mais comuns: design têxtil, design cerâmico, design em porcelana, plástico e papel. Partindo para um ponto de vista mais subjetivo, vale ressaltar que "As superfícies devem possuir ferramentas para se relacionar com o homem e seu ambiente de forma ativa, permitindo a interação em todos os sentidos, com seu público, com o local em que se encontra e com seu próprio volume". (FREITAS, 2011, p. 16-17).

Ressaltamos que, as superfícies não são apenas bidimensionais, podem ser o próprio objeto tridimensional, como uma calçada, por exemplo, construída a partir do encaixe de módulos. Além disso, conforme salienta Gurgel (2005, p. 36), “Uma mesma superfície, dependendo da textura com que for revestida, pode causar diferentes reações ou sensações. Uma mesma textura, dependendo do tipo de iluminação que receba, pode ser percebida de maneiras diferentes".

Para Freitas (2011, p. 19), o processo criativo responsável pelo desenvolvimento de novas superfícies "[...] se apresenta como uma teia de ideias e pensamentos regidos por forças internas do autor e exigências externas advindas do momento histórico-cultural, de questões econômicas e de valores da sociedade". Freitas (2011, p. 25) destaca que essas forças internas "envolvem o campo de escolhas pessoais, crenças, gostos e valores do designer diante das relações de caráter externo referentes ao momento cultural e histórico em que o designer está inserido [...]".

E para que o processo criativo possa fluir livremente, é necessário que o designer seja, não apenas o criador, mas o articulador em relação às interferências, às rupturas e aos momentos de retroceder provenientes de todas as partes envolvidas, ou seja, a criação é coletiva, e "os produtos gerados são resultados da multiplicidade e da interdisciplinaridade entre essas conexões". (FREITAS, 2011, p. 26).

Os trabalhos são realizados a partir de meios práticos e simbólicos que possuem relações únicas em seu processo criativo. Freitas acrescenta que é função do 
designer de superfície "[...] tratar, explorar e ressaltar a interface comunicativa dos objetos, unindo características funcionais e estéticas que se apresentam também em outras especialidades, porém em cada uma, tais fatores possuem importâncias específicas".

\subsection{Biblioteca pública}

A biblioteca pública, segundo a Fundação Biblioteca Nacional (2000, p. 17), “[...] é o espaço privilegiado das práticas leitoras, e através do encontro do leitor com o livro forma-se o leitor crítico e contribui-se para o fortalecimento da cidadania". A biblioteca pública destina-se essencialmente ao ato de ler, disponibilizando conhecimento e informação a partir de diferentes meios e para todos os membros da sociedade.

"O conceito de biblioteca pública baseia-se na igualdade de acesso para todos, sem restrição de idade, raça, sexo, status social, etc. e na disponibilização à comunidade de todo tipo de conhecimento. Deve oferecer todos os gêneros de obras que sejam do interesse da comunidade a que pertence, bem como literatura em geral, além de informações básicas sobre a organização do governo, serviços públicos em geral e publicações oficiais. A biblioteca pública é um elo de ligação entre a necessidade de informação de um membro da comunidade e o recurso informacional que nela se encontra organizado e à sua disposição." (FBN, 2000, p. 17).

Com quatro funções principais (educativa, cultural, recreativa e informacional), a gestão de uma Biblioteca Pública deve manter as funções intimamente ligadas, não sendo possível trabalhá-las separadamente. De acordo com Arruda (1999, p.10), a função educativa compreende "as atividades que servirão exclusivamente, como complemento, suporte e apoio à educação formal", definida por Andrade e Magalhães (1979) como obrigatória, isto é, crucial para a manutenção da sociedade porque incute valores e informações padronizados. Mueller (1984) acrescenta que esta função não deve ser entendida como sendo a mesma da escola ou da educação de massa, pois a biblioteca deve visar o benefício da sociedade através da prática de leitura, ou seja, estimulando o uso dos livros.

A função cultural compreende todo e qualquer tipo de manifestação artística oferecida à comunidade, dando aos indivíduos a oportunidade de contato, participação e apreciação das artes. Isso significa que a biblioteca poderia oferecer desde uma programação de música clássica até algumas sessões de cinema, abrangendo, também, um acervo de literatura em nível variado, palestras, exposições, cursos e tudo mais que se possa imaginar em favor da cultura. É importante ressaltar que a biblioteca pública não tem a pretensão de ocupar o espaço dos museus, galerias de artes ou instituições afins, ela apenas concebe a cultura como algo que leva ao refinamento, deixando de lado a incultura, a ignorância e a rudeza. (ARRUDA, 1999).

A função recreativa ou de lazer, apesar de ser vista como a que mais perde espaço junto aos meios de comunicação, visa atender a uma importante necessidade social: o equilíbrio psíquico. Sua finalidade, segundo Arruda (1999, p. 12) é oferecer "uma leitura descompromissada e de livre escolha para proporcionar ao público que a procura o relaxamento e/ou recreação do indivíduo, cuja rotina encontra-se inserida nas pressões exercidas pela vida moderna", ou seja, é uma forma de evasão e de 
compensação que pode gerar um interesse pelos demais gêneros literários existentes no acervo da biblioteca.

Nesse sentido, a recreação também deve beneficiar o público infantil, com um local reservado para as crianças, "contendo livros, jogos, brinquedos e gibis apropriados para cada faixa etária, TV e vídeo, palco para representações, a fim de despertar o raciocínio, coordenação motora e, sobretudo, o gosto pela leitura". (ARRUDA, 1999, p. 13). A função informacional, segundo Andrade e Magalhães (1979), refere-se ao acesso a informações que a biblioteca deve oferecer de forma cada vez mais confiável, rápida e, principalmente, com qualidade. Esta função pode ser exercida em três áreas: apoio à educação formal (fornecimento de obras que incentivam a pesquisa pelos estudantes); serviço de informação para a comunidade, em que a biblioteca funciona como um centro referencial na busca de soluções para problemas da vida cotidiana; e serviço de informação para a indústria.

É importante ressaltar que essas quatro funções não caminham isoladamente, pois, somente através da união entre elas é que a biblioteca poderá tornar-se uma instituição verdadeiramente pública. As funções atribuídas à biblioteca pública se caracterizam fundamentalmente por: destinar-se a toda coletividade; possuir todo tipo de material (sem restrições de assuntos ou de materiais); ser subvencionada pelo poder público (federal, estadual ou municipal). (FBN, 2000).

\section{PROCEDIMENTOS METODOLÓGICOS}

O presente capítulo apresenta o enfoque metodológico utilizado nesta pesquisa. Com a finalidade de identificar referências que apontem a participação do ecodesign como forma de valorização da biblioteca pública em projetos de design de superfície, buscou-se na investigação local analisar o ambiente. Desta forma, procurase, aqui, descrever a natureza e a caracterização da pesquisa, as técnicas de coleta de dados utilizadas, os critérios de análise, finalizando com considerações acerca dos aspectos limitantes do estudo.

Método é definido por Marconi e Lakatos (2010) como um conjunto de atividades sistemáticas e racionais que, com maior segurança e economia, permite alcançar o objetivo da pesquisa, traçando o caminho a ser seguido, detectando erros e auxiliando as decisões do pesquisador. Nesses termos, esta pesquisa pode ser considerada:

- Quanto aos objetivos: exploratória e descritiva. A pesquisa exploratória visa a busca de maiores informações sobre a realidade existente, descrevendo-a de maneira coerente e concisa. E a pesquisa descritiva tem como objetivo a descrição das características de determinado fenômeno, bem como o estabelecimento de relações entre variáveis e fatos. (MARTINS, 2012).

- Quanto aos procedimentos: pesquisa bibliográfica e estudo de caso. A pesquisa bibliográfica serve para fundamentar o tema da pesquisa com base em referências publicadas em livros e artigos, visando conhecer, analisar e explicar contribuições sobre o assunto abordado. (MARTINS; THEÓPHILO, 2007). O estudo de caso, por sua vez, visa o estudo de um fenômeno da vida real, "onde o pesquisador não tem controle sobre eventos e variáveis, buscando apreender a totalidade de uma situação e, criativamente, descrever, compreender e interpretar a complexidade de um caso concreto". (MARTINS; THEÓPHILO, 
2007, p. 61). As principais fontes de evidências do estudo de caso são: documentação, registros em arquivos, entrevistas, observações diretas, observação participante e artefatos físicos.

- Quanto à abordagem: qualitativa. A pesquisa qualitativa requer descrição, compreensão, interpretação e análise de informações, dados e evidências da problemática em questão. (MARTINS; THEÓPHILO, 2007).

Os dados e informações relevantes para solucionar o problema da pesquisa foram obtidos por meio de pesquisa bibliográfica e estudo de caso. A pesquisa bibliográfica proporcionou o embasamento teórico de dois campos do design: ecodesign e design de superfície, possibilitando definir e delimitar o tema da pesquisa. Já o estudo de caso possibilitou a observação direta da biblioteca pública de Guaraciaba.

Para Yin (2010), as observações diretas podem ser feitas durante a visita de campo, incluindo as ocasiões em que outras evidências estão sendo coletadas. A observação direta do ambiente se deu no momento da visita à biblioteca. Os aspectos observados foram os seguintes: condições físicas do edifício, estrutura da biblioteca quanto à capacidade de atender o público leitor, localização dos móveis e do acervo, iluminação, ventilação, cores, revestimentos etc.

A análise dos dados foi realizada a partir de descrições detalhadas sobre o ambiente de estudo. Trata-se de uma análise indutiva, pois, os dados são analisados à medida que são coletados, formando-se ou consolidando-se abstrações desse processo. Por ser uma pesquisa qualitativa, este estudo tem como preocupação central descrições, compreensões e interpretações dos fatos ao invés de medições. (MARTINS; THEÓPHILO, 2007).

\section{ANÁLISE DOS DADOS E RESULTADO}

\subsection{Biblioteca pública de Guaraciaba}

A biblioteca de Guaraciaba, Santa Catarina, foi fundada em 27 de agosto de 1960 e localizava-se no Colégio Estadual Sara Castelhano Kleinkauf. Em março de 2006, a mesma foi desmembrada do colégio, passando a ser pública e a pertencer ao município. Desde então, localiza-se junto ao Centro de Múltiplo Uso Armando Domingos Montagna.

Os livros que hoje pertencem ao acervo da biblioteca são oriundos de doações da comunidade e abordam os mais diversos assuntos: literatura infantil e juvenil, literatura brasileira, religião, educação, português, informática, ciências, matemática, biologia, geografia, ecologia, psicologia, filosofia, medicina, saúde, literatura e poesia catarinense, história de Santa Catarina e do Rio Grande do Sul e história geral.

A estrutura da biblioteca é de alvenaria pintada em bom estado de conservação. A iluminação e a ventilação utilizadas são naturais e artificiais. As paredes e a maioria dos móveis apresentam coloração marfim, estes também apresentam alguns detalhes em preto. Os revestimentos utilizados são, nas paredes e no teto, tinta de parede; e no piso de toda edificação, a cerâmica.

A biblioteca também possui um espaço integrado com computadores, para acesso à internet e auxílio às pesquisas, e outro com mesas e cadeiras para estudos em grupo. De acordo com o bibliotecário, os leitores são de todas as idades e classes sociais. Para ele, o número de visitas ao acervo é baixo devido a diversos fatores, 
dentre os quais destaca: publicações antigas e existência de outra biblioteca no colégio estadual, a qual é bastante frequentada pelos estudantes.

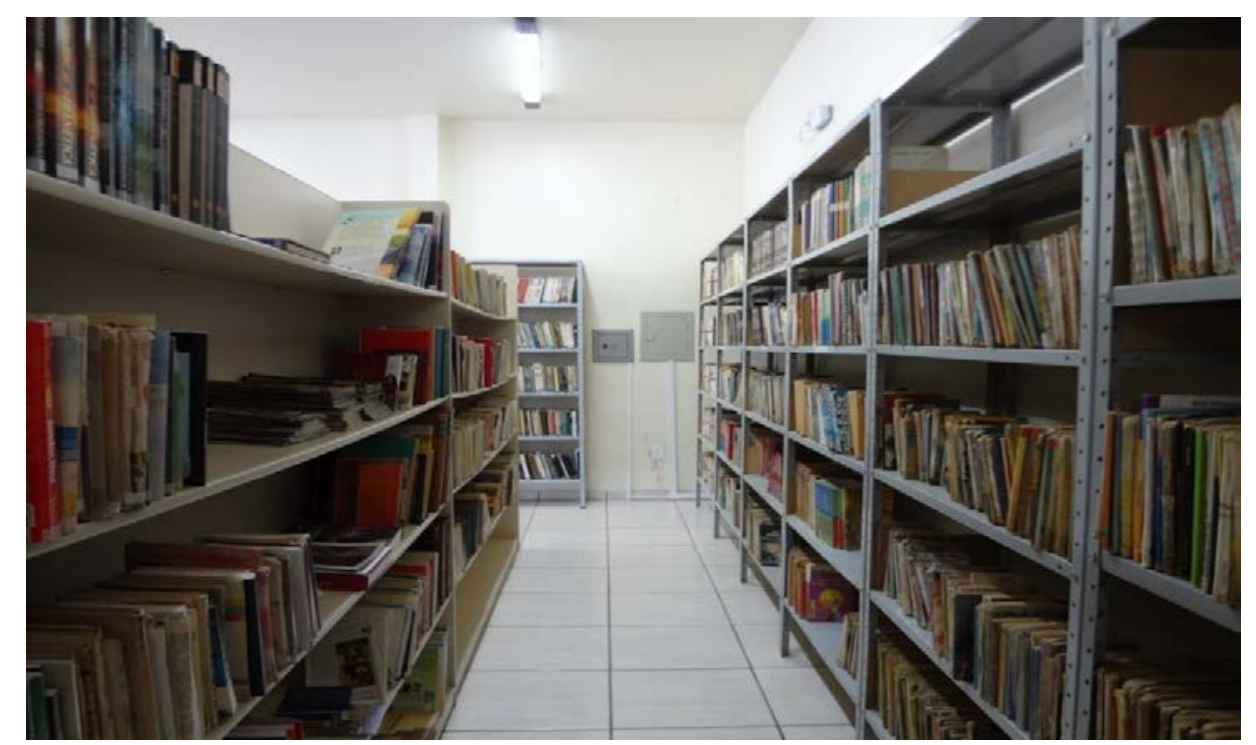

Figura 1 - Acervo da Biblioteca.

Fonte: Acervo dos autores, com base na pesquisa.

\subsection{Ecodesign: resíduos da madeira}

O foco do ecodesign neste estudo é a reutilização da madeira, de diversas espécies, proveniente do descarte em indústrias moveleiras e de esquadrias, localizadas no extremo oeste catarinense. Os resíduos provenientes da madeira podem ser classificados em três tipos: serragem, cepilho e lenha (Figura 2). Conforme Hillig e outros (2006), a serragem é um resíduo originado da operação de serras; o cepilho, também conhecido como maravilha, é gerado das plainas de beneficiamento; e a lenha é um resíduo de maiores dimensões, composta por costaneiras, aparas, refilos, restos de lâminas. Por apresentar possibilidades criativas, optou-se por trabalhar com os resíduos do tipo lenha, que foram separados de acordo com o tamanho e o formato (Figura 3). Os resíduos utilizados neste estudo apresentam as seguintes dimensões: $80 \times 60 \times 10 \mathrm{~mm}$ e $35 \times 20 \times 10 \mathrm{~mm}$ para retângulos, considerando comprimento, largura e profundidade; $92,2 \times 70 \times 60 \times 10 \mathrm{~mm}$ para triângulos escalenos, e, $21,2 \times 15 \times 15 \times 10 \mathrm{~mm}$ para triângulos isósceles, considerando os três lados e a profundidade.
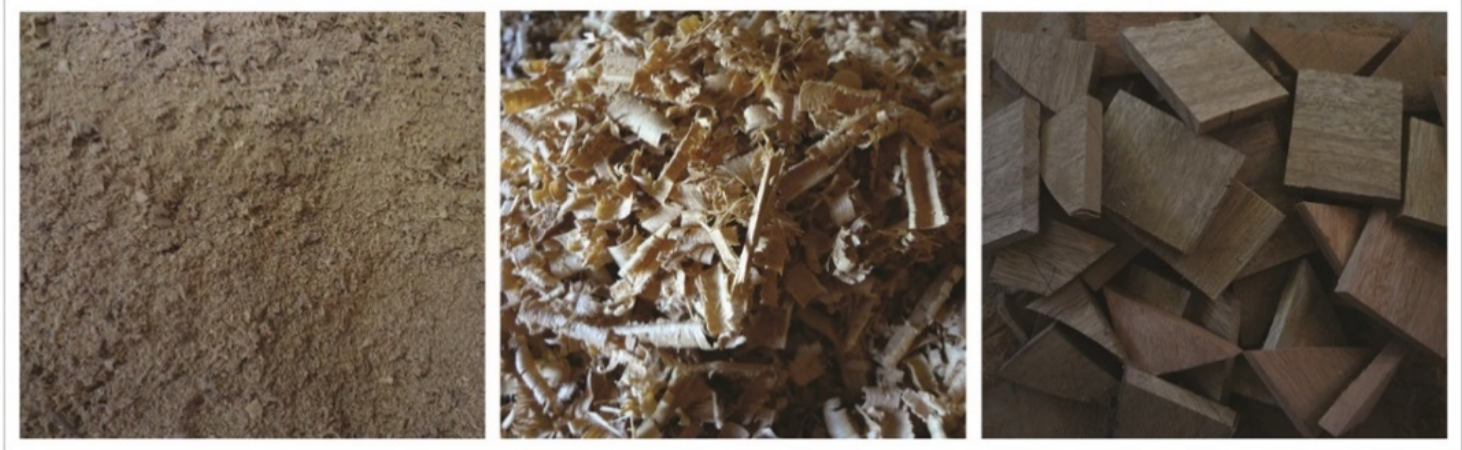

Figura 2 - Resíduos de madeira (serragem; cepilho; lenha).

Fonte: Acervo dos autores. 

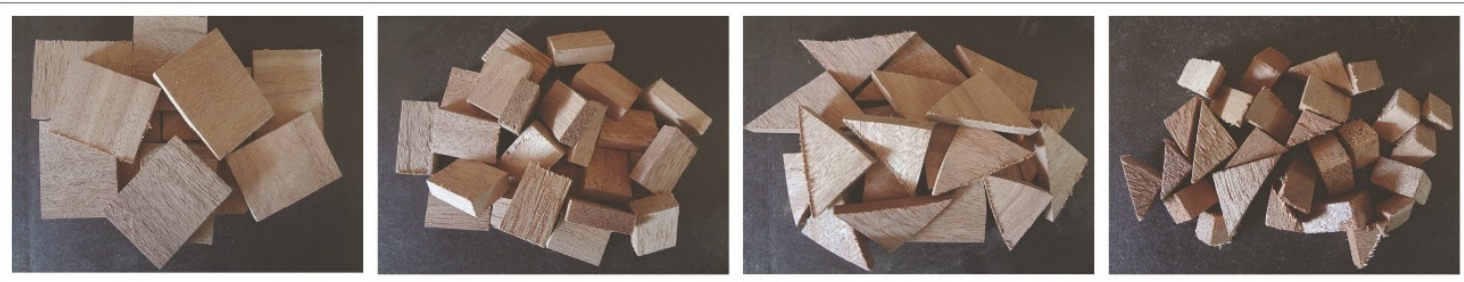

Figura 3 - Formatos e tamanhos dos resíduos Fonte: Acervo dos autores.

Reutilizar significa utilizar novamente materiais descartados, em sua forma original, para fabricação de outros produtos, visando, desta forma, eliminar os resíduos produzidos pelas indústrias e diminuir o impacto no ambiente. Os resíduos do tipo lenha acima apresentados, até o presente momento não são descartados corretamente pela maior parte das indústrias, sendo, na maioria das vezes, queimados. Uma das razões para isso é o grande volume que apresenta.

\subsection{Design de superfície: elaboração}

Partíamos do princípio que em Projeto de Produto, o Design industrial é a síntese criativa de fatores projetuais e de elementos simétricos; o conjunto de atitudes e comportamentos que se apresentam ao longo do processo de projetação, ou seja, o desenho é a base gráfica para a criatividade em projetos. Projetar superfícies pode ser fascinante quando o designer industrial estiver em contato direto com o material de estudo, principalmente pelo seu caráter sinestesial (tato, visão e olfato juntos). Isto dá ao designer industrial de superfície grande motivação (pessoal e/ou profissional) para desenvolver o projeto.
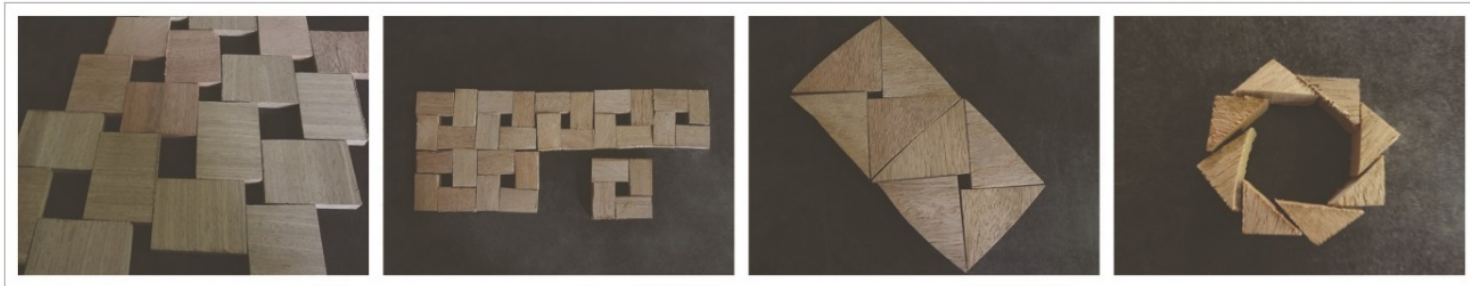

Figura 4 - Encaixe dos resíduos.

Fonte: Elaborado pelos autores, com base na pesquisa realizada.

Para criar os padrões a seguir apresentados, utilizou-se a técnica de encaixe com os pedaços de madeira dispostos sobre uma bancada (Figura 4). A partir de então, as quatro combinações elaboradas foram redesenhadas em aplicativos 2D, uma combinação diferente para cada tamanho de resíduo (Figura 5). As superfícies criadas foram pensadas no máximo aproveitamento dos resíduos, limitando as peças apenas aos processos de lixamento, para facilitar o encaixe; e pintura em verniz, para melhor acabamento, conservação e valorização do material. 

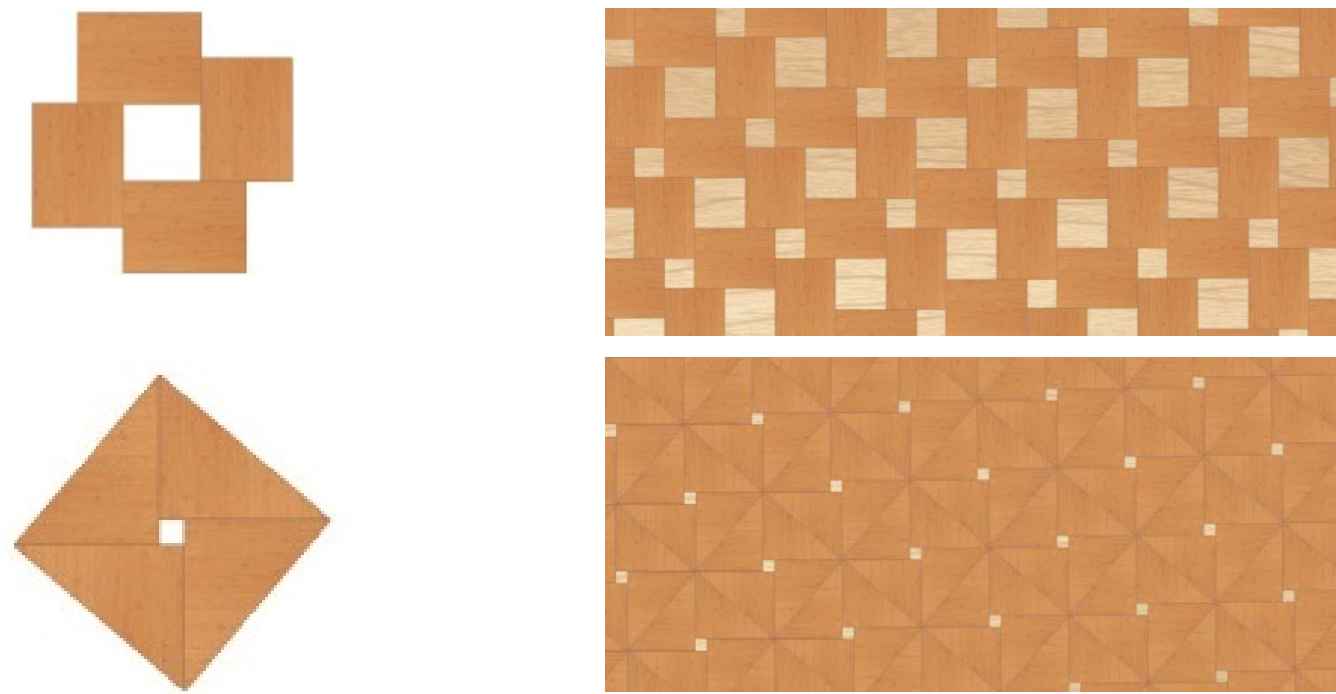

Figura 5 - Sistema de repetição e módulo I, II.

Fonte: Elaborado pelos autores, com base na pesquisa.

Tanto os módulos quanto os sistemas de repetição desenvolvidos podem ser estudados e/ou arranjados de inúmeras outras maneiras, visto que a geometria das peças proporciona essas variações, como por exemplo, criar superfícies mais, ou menos, vasadas.

\subsection{Resultado do estudo}

Conforme visitas realizadas na biblioteca pública de Guaraciaba, foram levantadas informações acerca das dimensões do ambiente, do mobiliário e demais objetos que o compõem a fim de redesenhar o ambiente em software 3D. Para que as superfícies pudessem ser aplicadas de maneira mais eficiente, ou seja, abrangendo uma área relativamente grande nas paredes do ambiente, optou-se por sugerir esta aplicação nas paredes mais próximas à entrada, por não possuírem estantes à sua frente e pela visibilidade.
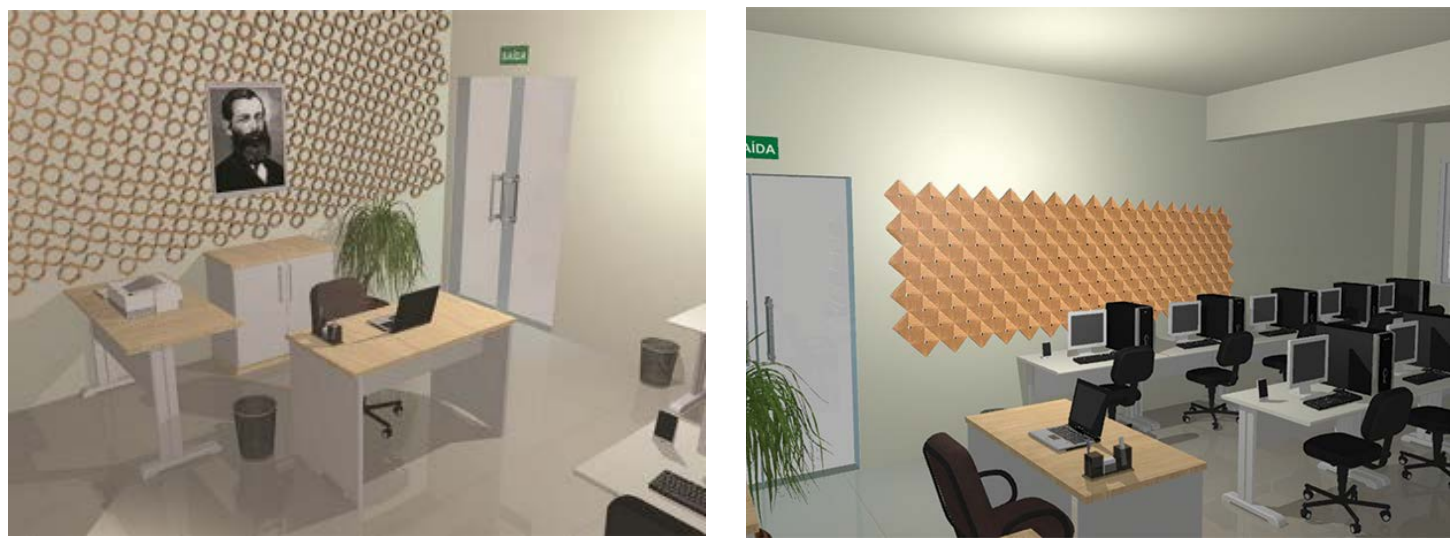

Figura 6 - Propostas de aplicação das superfícies. Fonte: Acerco dos autores.

A madeira, na condição de material de revestimento, incorpora "um conjunto de características técnicas e econômicas que dificilmente se encontram em outro 
material. Apresenta boas condições naturais de isolamento térmico e absorção acústica, é leve em peso e tem grande resistência mecânica". (BAUER, 2001, p. 437 apud PEIXE; LICHESKI, 2010, p. 3). Ideal para o espaço interno da biblioteca, visto que é um ambiente público e que precisa de silêncio para que as práticas leitoras se desenvolvam harmoniosamente. Peixe e Licheski (2010, p. 4) destacam que "A madeira é um material orgânico, caloroso, e sua utilização pode criar ambientes acolhedores, que refletem o caráter de lar. Um espaço no qual predomina o uso do material em geral é convidativo à permanência".

\section{CONCLUSÃO}

Os resultados deste estudo apontam que a criação de superfícies a partir da reutilização da madeira é importante alternativa para minimizar o impacto ambiental causado por este tipo de resíduo. Mesmo com a simulação da aplicação das superfícies no interior da biblioteca pública de Guaraciaba, é possível perceber a harmonia que a madeira proporciona ao ambiente, tanto por sua textura quanto pela composição.

A aplicação do ecodesign vem ao encontro de um dos maiores desafios da sociedade moderna: a sustentabilidade ambiental. O ecodesign aplicado em um ambiente público e com a utilização de um material disponível na região, além de servir de exemplo, torna o ambiente mais convidativo e aconchegante.

Este estudo corrobora com as definições apresentadas por Cândido e Rubim no que se refere ao ecodesign e ao design de superfície, respectivamente. Pois, para Cândido (2008), a reutilização de materiais contribui para a diminuição do impacto ambiental e para a redução do consumo de energia na indústria; e, para Rubim (2010), qualquer superfície pode receber um projeto. É de grande valia o designer expressar suas escolhas pessoais diante do momento histórico e cultural em que está inserido, conforme mencionado por Freitas (2011).

Por fim, conclui-se que o ecodesign aliado ao design de superfície torna-se uma importante ferramenta para transformar um ambiente, para torná-lo esteticamente mais agradável e confortável. Desta forma, sugere-se outros estudos na área bem como a aplicação das superfícies criadas nos mais diversos ambientes, não limitando apenas à biblioteca pública.

\section{REFERÊNCIAS}

ANDRADE, Ana Maria Cardoso de. MAGALHÃES, Maria Helena de Andrade. Objetivos e funções da biblioteca pública. Revista da Escola de Biblioteconomia da UFMG, Belo Horizonte, v.8, n.1, p. 48-59, mar. 1979.

ARRUDA, Guilhermina Melo. As práticas da biblioteca pública a partir das suas quatro funções básicas. 1999. Disponível na internet por http em: $<$ http://bibliotecaproduz.files.wordpress.com/2009/06/as-praticas-da-bibliotecapublica-katty.pdf>. Acesso em 23 out. 2013.

BÜRDEK, Bernhard E. História, teoria e prática do design de produtos. 1. ed. São Paulo: Edgard Blücher, 2006. 496 p.

CÂNDIDO, Luis Henrique Alves. Contribuição ao estudo da reutilização, redução e da reciclagem dos materiais com aplicação do Ecodesign. 2008. 130 f. Dissertação (Mestrado em Engenharia)-UFRGS, Porto Alegre, 2008. 
COSTA et al. Design e naturalismo: filosofia naturalista, biônica e ecodesign. Design, Arte, Moda e Tecnologia. São Paulo: Rosari, Universidade Anhembi Morumbi, PUC-Rio e Unesp-Bauru, 2010. Disponível na internet por http em:

<http://sitios.anhembi.br/damt6/arquivos/02.pdf>. Acesso em 10 jun. 2014.

FREITAS, Renata Oliveira Teixeira de. Design de superfície: as ações comunicacionais táteis nos processos de criação. 1. ed. São Paulo: Edgard Blucher, 2012. 106 p. (Coleção Pensando o Design).

FUNDAÇÃO BIBLIOTECA NACIONAL, Coordenadoria do Sistema Nacional de Bibliotecas Públicas. Biblioteca pública: princípios e diretrizes. Rio de Janeiro: Fundação Biblioteca Nacional, Dep. de Processos Técnicos, 2000. 160 p.

GURGEL, Miriam. Projetando espaços: guia de arquitetura de interiores para áreas comerciais. 3. ed. rev. São Paulo: Senac São Paulo, 2005.

HILLIG et al. Resíduos de madeira da indústria madeireira: caracterização e aproveitamento. In: ENEGEP, 26., 2006, Fortaleza. ABEPRO. Fortaleza, 2006.

MARCONI, Marina de Andrade; LAKATOS, Eva Maria. 2010. Fundamentos de metodologia científica. 7. ed. São Paulo: Atlas, 2010. 297 p.

MARTINS, Gilberto de Andrade. Manual para elaboração de monografias e dissertações. 3. ed. 7. reimpr. São Paulo: Atlas, 2012. 136 p.

MARTINS, Gilberto de Andrade; THEÓPHILO, Carlos Renato. Metodologia da investigação científica para ciências sociais aplicadas. São Paulo: Atlas, 2007. 226 p.

MESACASA, Andréia; CORONA, Hieda Maria Pagliosa; MELLO, Nilvânia Aparecida. Ecodesign: um novo paradigma moderno inscrito entre moda e consumo? Design e Tecnologia, Porto Alegre: PgDesign UFRGS, n. 2, p. 1-7, 2010. Disponível na internet: <http://www.pgdesign.ufrgs.br/designetecnologia/index.php/det/article/view/14>. Acesso em 26 mar. 2014.

MUELLER, S. P. M. Bibliotecas e sociedade: evolução da interpretação de função e papéis da biblioteca. R. Esc. Bibliotecon, Belo Horizonte: UFMG, v. 13, n. 1, p. 7-54, mar. 1984.

PEIXE, M. A.; LICHESKI, L. C. O uso e as sensações da madeira no espaço interno. In: CONGRESSO BRASILEIRO DE PESQUISA E DESENVOLVIMENTO EM DESIGN, 9., 2010, São Paulo. Anais P\&D Design. São Paulo, 2010. Disponível na internet por http em: <http://blogs.anhembi.br/congressodesign/anais/artigos/69460.pdf>. Acesso 150415.

RUBIM, Renata. Desenhando a superfície. 2. ed. rev. e atual. São Paulo: Rosari, 2010.

STRALIOTTO, L. M. Ecodesign aplicado ao design de joias. UFRGS. Disponível na internet por http em: <http://www.coloquiomoda.com.br/anais/anais/4-Coloquio-deModa_2008/42377.pdf>. Acesso em 03 out. 2014.

STRALIOTTO, L. M.; GONÇALVES, G. F. Ecodesign aplicado ao design de joias. In: CONGRESSO BRASILEIRO DE PESQUISA E DESENVOLVIMENTO EM DESIGN, 8., 2008, São Paulo. Anais P\&D Design. São Paulo: UFRS, 2008.

<http://www.modavestuario.com/503ecodesignaplicadoaodesigndejoias.pdf>.

YIN, R. K. Estudo de caso: planejamento e métodos. 4. ed. Porto Alegre: Bookman, 2010. 